\title{
Malignant hypertension: does this still exist?
}

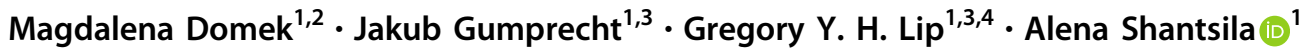

Received: 5 August 2019 / Revised: 22 September 2019 / Accepted: 23 September 2019 / Published online: 21 October 2019

C) Springer Nature Limited 2019

Malignant hypertension (MHT) is the most severe form of hypertension. It was originally defined by two major features: extremely high blood pressure with the diastolic blood pressure above $130 \mathrm{mmHg}$ at the time of the diagnosis and hypertensive retinopathy grades III or IV in the Keith et al.'s classification [1].

More recently, the definition of MHT has been reconceptualized to emphasis multi-organ damage [2, 3]. Indeed, overall prognosis in patients with MHT mainly depends on the function of kidney, brain, and heart [3]. As the earlier diagnosis and appropriate antihypertensive treatment result in significant improvement of prognosis [4], it is of the utmost importance to set reliable diagnostic criteria. Hence, the proposed new definition presents MHT as a group of the concomitant damage of at least three different target organs [3]. Considering the disease entity in a broader perspective will allow to increase the detection and estimate the real prevalence of this hypertensive emergency.

The principals of prompt detection, systemic evaluation, and effective management are the key to improve the longterm prognosis. disorders with out of range elevation in blood pressure with

\section{Epidemiology}

In general population the prevalence of MHT is relatively low with annual incidence rate of around 2 per 100,000 of Caucasian population [5, 6]. Greater disease predisposition and worse prognosis is observed in the Afro-American population (7.3 new cases per 100,000 of population per year) [6]. There is also no significant difference in MHT prevalence between developed and developing countries $[7,8]$.

As a hypertensive emergency MHT might develop in patients with prior history of essential hypertension, but in up to $60 \%$ cases MHT occurs de novo with no differences in signs and symptoms or long-term survival [9].

In the past, MHT had an unfavorable prognosis and without adequate treatment, mortality rate in MHT was around $80 \%$ at 2 years [10]. Importantly, 5-year survival among MHT patients has improved dramatically over the decades and for patients diagnosed after 1997 it is now more than $90 \%$ [11]. When compared malignant and nonMHT all-cause mortality is higher, with kidney failure as the main cause of death among patients with MHT $[12,13]$. Nevertheless, since the new, more effective antihypertensives are in use, current prognosis performs better [2]. Despite the overall decrease, the prevalence has been roughly stable for the last 40 years [4].

\section{Diagnostic difficulties}

s.shantsila@liverpool.ac.uk

1 Liverpool Centre for Cardiovascular Science, University of Liverpool, Liverpool John Moores University and Liverpool Heart \& Chest Hospital, Liverpool, UK

2 Department of Internal Diseases, Diabetology and Nephrology, Silesian Medical University, Zabrze, Poland

3 Department of Cardiology, Congenital Heart Diseases and Electrotherapy, Silesian Medical University, Silesian Centre for Heart Diseases, Zabrze, Poland

4 Aalborg Thrombosis Research Unit, Department of Clinical Medicine, Aalborg University, Aalborg, Denmark
MHT may pose a diagnostic challenge whilst early diagnosis is essential for prompt treatment [3, 14]. As emphasized, the MHT has a significantly worse prognosis than the non-MHT, and it appears this difference is mainly due to renal insufficiency resulting in end-stage renal disease. Moreover, the main diagnostic problem is caused by the lack of obvious symptoms which flag out patients who require further investigation, that is fundoscopy. The latter is an essential examination required to establish an initial diagnosis based on the original criteria. Thus, retinal 
fundoscopy should be performed in all patients presenting with severely increased blood pressure on examination [2]. It is due to the fact that typical retinal changes are dynamic, start to regress immediately upon the implementation of the antihypertensive treatment and do not persist for longer than 2-3 months [2, 15].

Although in some cases, when patients present with extreme signs of blood pressure elevation, such as hypertensive encephalopathy and MHT is suspected, Grade 3-4 ocular changes might be absent during their initial examination [16]. There are also other disorders which might cause papilledema or retinal hemorrhages, such as severe anemia, ineffective endocarditis, or connective tissue disorders [17]. Not to mention also diabetic retinopathy, which is a leading cause of sight impairment and retinal changes [18]. All the above disrupt and complicate the differential diagnosis. As the clinical presentation of MHT is often delayed, the presence of ocular fundus changes before initiating treatment should not be a determinant [3]. Moreover, changes in the vision correspond to the renal function impairment $[19,20]$.

The common cause of the described alternations is systemic microvascular dysfunction. An important pathological feature of MHT is endothelial dysfunction and fibroid necrosis of arterioles, that obviously concerns various tissues and affects many organs, especially key ones, that is kidney, heart, and brain $[2,21]$. This premise lay the foundation for the evolution of definition in which the concept of multi-organ damage, described as hypertensive target organ damage (TOD), was introduced [2, 3, 21]. Other diagnostic criteria required are the presence of damage of at least three different target organs (kidney, heart, brain, and small vessels) and out of range elevation in systolic and diastolic blood pressure.

Renal abnormalities are the most common evidence of TOD and constitutes an independent determining factor in prognosis [22]. MHT exerts various impacts on the kidney, from elevated serum creatinine and proteinuria to acute renal failure as a first presentation of MHT [23, 24]. Moreover, renal ischemic changes are aggravated by hemolysis and low plate platelet count, resulting from thrombotic microangiopathy $[3,25]$.

In the heart, the impairment of cardiac structure and function is so evident that it is referred as hypertensive heart disease [26]. It includes left ventricular hypertrophy, cardiomegaly, systolic and diastolic dysfunction, and finally heart failure [9, 27]. Even atrial fibrillation is said to be a certain presentation of TOD [27].

Prevention of neurological deficits is a crucial goal in MHT treatment, especially because of their oftenasymptomatic course and limited diagnostic possibilities. However, the most life-threatening condition, hypertensive encephalopathy, is a rare emergency with sudden onset of symptoms that facilitates differential diagnostics [2, 28].

\section{Treatment}

The hypertensive emergencies require immediate intervention to lower blood pressure [29]. It is important to reduce the blood pressure in appropriate pace, which is $\sim 20-25 \%$ decrease within several hours [30]. Too rapid blood pressure reduction may result in severe multi-organ ischemia caused by hypoperfusion and failure of autoregulation mechanisms [16, 31]. The conventional "normal" level of blood pressure should not be aimed at acute presentation with MHT [32]. First line pharmacological agents are labetalol and nicardipine. Alternatively nitroprusside and urapidil can be used as safe and effective treatment of MHT [30], as recommended by the ESC position document. Labetalol is an alpha 1 adrenergic receptor and nonselective beta-adrenergic receptor blocker. Its main advantage is capacity to both maintenance of cardiac output and reduction of peripheral resistance with preservation of cerebral, renal, and coronary blood flow [33]. Nicardipine, a dihydropyridine derivative calcium channel blocker with cerebral and coronary vasodilatory activity, increases stroke volume and coronary blood flow and it is especially recommended for patients with coronary artery disease[34]. Alternatively, some groups use very low oral dose of angiotensin-converting enzyme inhibitors [35] or renin-angiotensin system blockers [36] titrated over $48 \mathrm{~h}$, to prevent excessive fall in blood pressure. Although the preferable therapeutic approach for each patient depends on clinical presentation, the optimal clinical care is often be provided in the intensive care units to ensure adequate monitoring and treatment adjustments [37].

\section{New definition}

The original definition of MHT was focused only on visual disturbance and did not include other evidence of organ damage [1]. Such TOD, especially the severity of renal impairment, is pivotal in overall prognosis [38]. Along with the development of techniques for TOD assessment, a new definition has been widened to include the presence of impairment in at least three different organs including kidney, heart, brain, and microangiopathy [3]. They constitute various clinical presentations of the same disease entity $[2,3]$.

The current 2018 ESC/ESH Guidelines for the management of arterial hypertension present new, broadened approach to the hypertensive emergencies [29]. A collective group of "hypertension urgencies and emergencies" was distinguished with a strong emphasis on magnitude of organ damage, described as hypertension-mediated organ damage [29]. Besides, the term of "malignant hypertension" was clarified as it refers to the poor prognosis when untreated 
[29]. It characterizes the condition of severe hypertension with concomitant retinopathy, microangiopathy, disseminated intravascular coagulation, encephalopathy, acute heart failure, or acute deterioration in renal function [29]. Updated guidelines also offer greater range of diagnostic possibilities depending on target organs affected and symptoms, divided on common and specific tests [29]. Hence, common diagnostic tests including 12-lead ECG, hemoglobin, platelet count, fibrinogen, creatinine, eGFR, urine albumin:creatinine ratio were included for routine testing with fundoscopy as a crucial part of the diagnostic workup. Specific tests such as troponin, CK-MB, echocardiography, CT or MRI brain, urine drug screen, etc., undeniably contribute to improvement in general management of MHT [2, 39].

\section{Conclusions}

Although general improvements in diagnosis of MHT has been made, this is still a common emergency, especially in the developing countries due to the growing population, undiagnosed hypertension, and low level of health care services. Moreover, the diagnosis is established when the target organ impairment occur therefore this condition is related to much worse outcome than the nonmalignant forms of hypertension [3].

Despite better prognosis and significantly improved survival rates, patients with MHT remain at high risk. Not only do they require special attention during hospitalization, but also after discharge, which include screening for secondary hypertension and frequent follow-up visits.

\section{Compliance with ethical standards}

Conflict of interest The authors declare that they have no conflict of interest.

Publisher's note Springer Nature remains neutral with regard to jurisdictional claims in published maps and institutional affiliations.

\section{References}

1. Keith NM, Wagener HP, Barker NW. Some different types of essential hypertension: their course and prognosis. Am J Med Sci. 1974;268:336-45.

2. Shantsila A, Lip GYH. Malignant hypertension revisited-does this still exist? Am J Hypertens. 2017;30:543-9.

3. Cremer A, Amraoui F, Lip GYH, Morales E, Rubin S, Segura J, et al. From malignant hypertension to hypertension-MOD: a modern definition for an old but still dangerous emergency. J Hum Hypertens. 2016;30:463-6.

4. Lane DA, Lip GYH, Beevers DG. Improving survival of malignant hypertension patients over 40 years. Am J Hypertens. 2009;22:1199-204.
5. Lip GY, Beevers M, Beevers G. The failure of malignant hypertension to decline: a survey of 24 years' experience in a multiracial population in England. J Hypertens. 1994;12: 1297-305.

6. van den Born B-JH, Koopmans RP, Groeneveld JO, van Montfrans GA. Ethnic disparities in the incidence, presentation and complications of malignant hypertension. J Hypertens. 2006; 24:2299-304.

7. Kadiri S, Olutade BO, Osobamiro O. Factors influencing the development of malignant hypertension in Nigeria. J Hum Hypertens. 2000;14:171-4.

8. Kadiri S, Olutade BO. The clinical presentation of malignant hypertension in Nigerians. J Hum Hypertens. 1991;5:339-43.

9. Lip GYH, Beevers M, Beevers DG. Do patients with de novo hypertension differ from patients with previously known hypertension when Malignant phase hypertension occurs? Am J Hypertens. 2000;13:934-9.

10. Leishman AW. Hypertension: treated and untreated; a study of 400 cases. Br Med J. 1959;1:1361-8.

11. Shantsila A, Shantsila E, Beevers DG, Lip GYH. Predictors of 5year outcomes in malignant phase hypertension: The West Birmingham Malignant Hypertension Registry. J Hypertens. 2017; 35:2310-4.

12. Amraoui F, Van Der Hoeven NV, Van Valkengoed IGM, Vogt L, Van Den Born B-JH. Mortality and cardiovascular risk in patients with a history of malignant hypertension: a case-control study. $\mathrm{J}$ Clin Hypertens. 2014;16:122-6.

13. Isles CG, Lim KG, Boulton-Jones $\mathrm{M}$, Cameron H, Lever AF, Murray G, et al. Factors influencing mortality in malignant hypertension. J Hypertens Suppl. 1985;3:S405-7.

14. Amraoui F, Bos S, Vogt L, van den Born B-J. Long-term renal outcome in patients with malignant hypertension: a retrospective cohort study. BMC Nephrol. 2012;13:71.

15. Steinegger K, Bergin C, Guex-Crosier Y. Malignant hypertension: clinical manifestations of 7 cases. Klin Monbl Augenheilkd. 2015;232:590-2.

16. Rodriguez MA, Kumar SK, De Caro M. Hypertensive crisis. Cardiol Rev. 2010;18:102-7.

17. Chen Y-H, Kuo H-K, Kao M-L. Malignant hypertensive retinopathy-clinical and fundus manifestations in patients with new onset or acute exacerbation of chronic hypertension. Chang Gung Med J. 2003;26:669-77.

18. Lee R, Wong TY, Sabanayagam C. Epidemiology of diabetic retinopathy, diabetic macular edema and related vision loss. Eye Vis. 2015;2:17.

19. Cortina G, Hofer J, Giner T, Jungraithmayr T. Severe visual loss caused by unrecognized malignant hypertension in a 15 -year-old girl. Pediatr Int. 2015;57:e42-e44.

20. Balogh Z, Berta A, Pfliegler G, Nagy V. Bilateral central retinal vein occlusion caused by malignant hypertension in a young patient. Clin Exp Hypertens. 2011;33:53-55.

21. Shantsila A, Dwivedi G, Shantsila E, Butt M, Beevers DG, Lip GYH. Persistent macrovascular and microvascular dysfunction in patients with malignant hypertension. Hypertension. 2011;57: 490-6.

22. Gonzalez R, Morales E, Segura J, Ruilope LM, Praga M. Longterm renal survival in malignant hypertension. Nephrol Dial Transplant. 2010;25:3266-72.

23. Shavit L, Reinus C, Slotki I. Severe renal failure and microangiopathic hemolysis induced by malignant hypertension-case series and review of literature. Clin Nephrol. 2010;73:147-52.

24. Gassanov N, Pollok M, Er F. Akutes Nierenversagen bei maligner Hypertonie [Acute renal failure associated with malignant hypertension]. Dtsch Medizinische Wochenschr. 2009;134: 2224-7. 
25. van den Born BJH, Honnebier UPF, Koopmans RP, van Montfrans GA. Microangiopathic hemolysis and renal failure in malignant hypertension. Hypertension. 2005;45:246-51.

26. Shantsila A, Dwivedi G, Shantsila E, Butt M, Beevers DG, Lip GYH. A comprehensive assessment of cardiac structure and function in patients with treated malignant phase hypertension: The West Birmingham Malignant Hypertension project. Int $\mathbf{J}$ Cardiol. 2013;167:67-72.

27. Lip GYH. Atrial fibrillation in patients with hypertension. Hypertension. 2016;68:544-5.

28. Vaughan CJ, Delanty N. Hypertensive emergencies. Lancet. 2000; 356:411-7.

29. Williams B, Mancia G, Spiering W, Rosei EA, Azizi M, Burnier $\mathrm{M}$, et al. $2018 \mathrm{ESC} / \mathrm{ESHGuidelines} \mathrm{for} \mathrm{themanagement} \mathrm{of} \mathrm{arterial}$ hypertension. J Hypertens 2018;36:1956-2041.

30. van den Born B-JH, Lip GYH, Brguljan-Hitij J, Cremer A, Segura J, Morales E, et al. ESC Council on hypertension position document on the management of hypertensive emergencies. Eur Hear J. 2019;5:37-46.

31. Papadopoulos DP, Sanidas EA, Viniou NA, Gennimata V, Chantziara V, Barbetseas I, et al. Cardiovascular hypertensive emergencies. Curr Hypertens Rep. 2015;17:5.

32. Gifford RW. Management of hypertensive crises. J Am Med Assoc. 1991;266:829-35.
33. Vidt DG, Bakst A, Pearce CJ, Wallin JD. Labetalol and other agents that block both alpha- and beta-adrenergic receptors. Cleve Clin J Med. 1994;61:59-69.

34. Turlapaty P, Vary R, Kaplan JA. Nicardipine, a new intravenous calcium antagonist: a review of its pharmacology, pharmacokinetics, and perioperative applications. J Cardiothorac Anesth. 1989;3:344-55.

35. Gosse P, Coulon P, Papaioannou G, Litalien J, Lemetayer P. Impact of malignant arterial hypertension on the heart. J Hypertens. 2011;29:798-802.

36. Rubin S, Cremer A, Boulestreau R, Rigothier C, Kuntz S, Gosse $\mathrm{P}$. Malignant hypertension: diagnosis, treatment and prognosis with experience from the Bordeaux cohort. J Hypertens. 2019; 37:316-24.

37. Varon J, Marik PE. Clinical review: the management of hypertensive crises. Crit Care. 2003;7:374-84.

38. Shantsila A, Lane DA, Beevers DG, Lip GYH. Lack of impact of pulse pressure on outcomes in patients with malignant phase hypertension. J Hypertens. 2012;30:974-9.

39. Lip GYH, Banerjee A, Boriani G, Chiang CE, Fargo R, Freedman B, et al. Antithrombotic therapy for atrial fibrillation CHEST guideline and expert panel report. Chest 2018;154: 1121-201. 